NBER WORKING PAPER SERIES

\title{
FINANCIAL FRICTIONS AND UNCONVENTIONAL MONETARY POLICY IN EMERGING ECONOMIES
}

\author{
Roberto Chang \\ Andrés Velasco \\ Working Paper 21955 \\ http://www.nber.org/papers/w21955 \\ NATIONAL BUREAU OF ECONOMIC RESEARCH \\ 1050 Massachusetts Avenue \\ Cambridge, MA 02138 \\ February 2016
}

Prepared for the 2015 IMF Annual Research Conference. We are grateful for comments and suggestions from Marcos Chamon and participants of seminars at CREI (Pompeu Fabra) and the Central Bank of Austria. The views expressed herein are those of the authors and do not necessarily reflect the views of the National Bureau of Economic Research.

NBER working papers are circulated for discussion and comment purposes. They have not been peerreviewed or been subject to the review by the NBER Board of Directors that accompanies official NBER publications.

(C) 2016 by Roberto Chang and Andrés Velasco. All rights reserved. Short sections of text, not to exceed two paragraphs, may be quoted without explicit permission provided that full credit, including $\odot$ notice, is given to the source. 
Financial Frictions and Unconventional Monetary Policy in Emerging Economies

Roberto Chang and Andrés Velasco

NBER Working Paper No. 21955

February 2016

JEL No. E52,E58,F41

\begin{abstract}
$\underline{\text { ABSTRACT }}$
We analyze conventional and unconventional monetary policies in a dynamic small open-economy model with financial frictions. In the model, financial intermediaries or banks borrow from the world market and lend to domestic households. Banks can borrow abroad up to a multiple of their equity; in turn, there is a limit to how much bank equity households can hold. An economy-wide credit constraint and an endogenous interest rate spread emerge from this combination of external and domestic frictions. The resulting financial imperfections amplify the domestic effects of exogenous shocks and make those effects more persistent. In response to external balance shocks, fixed exchange rates are contractionary and flexible exchange rates expansionary (although less so in the presence of currency mismatches); the opposite is true in response to increases in the world interest rate. Unconventional policies, including central bank direct credit, discount lending, and equity injections to banks, have real effects only if financial constraints bind. Because of bank leverage, central bank discount lending and equity injections are more effective than direct credit. Sterilized foreign exchange intervention is equivalent to lending directly to domestic agents. Unconventional policies are feasible only to the extent that the central bank holds a sufficient amount of international reserves.
\end{abstract}

\author{
Roberto Chang \\ Rutgers University \\ Department of Economics \\ 75 Hamilton Street \\ New Brunswick, NJ 08901 \\ and NBER \\ chang@econ.rutgers.edu \\ Andrés Velasco \\ Columbia University \\ School of International and Public Affairs \\ 420 West 118th Street \\ New York, NY 10027 \\ and Oxford University \\ and also NBER \\ avbranes@gmail.com
}




\section{Introduction}

In response to weakening commodity prices and higher interest rates in the U.S., emerging economies have suffered capital outflows, raising concerns about macro and financial vulnerabilities. This evolving scenario is also fueling debate on how policy should respond to these and similar shocks when they materialize. A central issue in the debate is whether and to what extent central banks in emerging countries should join their advanced country peers in implementing quantitative easing, credit easing, and other so-called unconventional monetary policies.

But discussions of this issue have been hampered by our very imperfect understanding of the rationale and implications of such unconventional policies. This is not surprising, given that dominant models of monetary policy have assumed complete and perfectly functioning financial markets, which imply that unconventional policies are redundant and irrelevant. ${ }^{1}$ This assumption is unrealistic for advanced economies and even more so for emerging economies, which often have ill-functioning financial markets and sizable stocks of dollar-denominated debt. In emerging economies, therefore, many questions remain wide open: How do financial frictions amplify exogenous shocks? Can the financial sector itself become a source of shocks? What are the implications for monetary policies of both the "conventional" and "unconventional" kinds? ${ }^{2}$

To tackle these questions, in this paper we develop a simple model of an emerging economy in which financial imperfections take center stage. We then use the model to analyze the impact of various real and financial shocks and the role of alternative monetary and exchange rate policies. While the model is mostly standard, dynamic, and built from first principles, we derive results analytically. To do so, we impose some special assumptions, so that our model may not be as general as others in the literature. But we believe its simplicity offers a compensating payoff in terms of insight and understanding, especially on the mechanics of conventional and unconventional policy.

Domestic financial frictions, combined with external financial frictions, can translate into an economy-wide foreign debt limit, with significant implications for aggregate demand and monetary policy. In our model, domestic

\footnotetext{
${ }^{1}$ As for dominant models, see Woodford (2003). The irrelevance of unconventional policies under perfect financial markets was originally shown in Wallace (1981).

${ }^{2}$ For further discussion of unconventional policies in advanced economies, see Gertler and Kiyotaki (2010). For emerging economies, see Céspedes, Chang, and Velasco (2014).
} 
residents cannot borrow abroad directly; instead, they borrow from domestic financial intermediaries or banks which, in turn, borrow abroad. Foreign credit to banks, however, has a limit that depends on the size of the banks' equity capital. A crucial question, therefore, concerns the determination of the financial sector equity base. We assume that intermediaries obtain equity capital from households, but the typical household in turn faces an exogenous upper limit to the amount of equity it can hold. This equity constraint is quite consequential. Presumably it can be derived from more fundamental domestic frictions, such as informational or enforcement imperfections, that result in an incomplete transfer of equity from households to banks. ${ }^{3}$ But for our purposes, the exact source of the equity constraint is not as critical as its implications.

One of these implications is that the binding domestic equity constraint becomes a binding international borrowing constraint, so that an endogenous spread between foreign and domestic interest rates emerges. Hence, in addition to standard transmission channels, our model features an interest rate channel of the type emphasized by Bernanke and Blinder (1988), Woodford (2010), and others. Movements in the spread reflect changes in the demand and supply for funds in the domestic loan market. The spread increases when the external debt constraint becomes tighter.

Another implication is that, when financial constraints are binding, the economy's external balance constraint determines how the economy responds to several kinds of shocks. With binding borrowing constraints, domestic agents cannot smooth out the effects of the shocks by running up debt. Hence the trade deficit has to adjust on impact, meaning that domestic consumption must fall or the real exchange rate has to depreciate, and by more than they would in a world with perfectly functioning capital markets. In other words, crucially, amplification of the shocks occurs.

Shocks that require such a drastic external adjustment, which we refer to as external balance shocks, include standard real shocks -for instance, temporary drops in foreign export demand. But external balance shockscan also arise in the financial sector. This is the case, if the equity constraint tightens, so that financial intermediaries suddenly have less capital, or if foreign lenders are suddenly willing to lend less to domestic financial intermedi-

\footnotetext{
${ }^{3}$ Here our model is reminiscent of the work by Caballero and Krishnamurthy (2003, for example). But their model is static and their analysis is concerned with a very different set of questions.
} 
aries, for a given amount of equity in the financial sector. All of these alternatives are conceptually different, but under binding financial constraints they all imply forced deleveraging: financial intermediaries, and by implication domestic households, have to reduce their debt abruptly. This captures what Dornbusch and Werner (1994) and Calvo (1998) termed sudden stops: overnight, capital inflows become capital outflows, and the trade account has to adjust quickly. If nominal prices are perfectly flexible, consumption and exports drop, and the real exchange rate depreciates sharply.

Adding the assumption of nominal price stickiness, we derive implications for monetary and exchange rate policies of both the conventional and the unconventional kind. We start with conventional policy, taking up the traditional question of fixed versus flexible exchange rates. Under a fixed exchange rate, the burden of adjusting to external balance shocks falls squarely on aggregate demand and production. Since borrowing is not possible, an external balance shock requires either increasing exports, cutting imports or both. But if the exchange rate is fixed by policy, external adjustment can only occur via a fall in imports and therefore in domestic consumption demand. Since output is determined by demand, output in turn drops. So in the face of adverse shocks, fixed exchange rates are contractionary.

Things are rather different if the exchange rate floats and, instead, there is a policy of fixing the interest rate. Adjusting to the same shocks then requires a real depreciation which in turn, and provided that export demand is not too price-inelastic, raises the dollar value of exports. Since the interest rate is constant so is consumption, but the dollar value of consumption and of imports both fall. This ensures external adjustment to the shock, even though the economy cannot borrow more in order to smooth out the consequences of the shock. Output goes up, since consumption is constant and exports rise. Under flexible exchange rates, therefore, these adverse shocks are expansionary.

These conclusions do not hinge on the presence of dollarization per se, since our baseline model assumes that equity claims and debts, both foreign and domestic, are denominated in foreign currency. But currency mismatches can be consequential. If the equity of banks is instead denominated in domestic currency while foreign loans remain denominated in dollars, an adverse shock that results in a real depreciation reduces the relative value of banks' equity, also cutting the capacity of the financial intermediary to borrow abroad. This causes further deleveraging which, in turn, requires an even larger real depreciation. In that sense, a currency mismatch is responsi- 
ble for added magnification of the effects of adverse shocks. These valuation effects are eliminated if the exchange rate is fixed, a result that may account for central bankers' alleged fear of floating.

While we emphasize external balance shocks, it is not too hard to extend our analysis to shocks of other types. In particular, we discuss the consequences of an increase in the world real rate of interest, which is of special interest given recent changes in US monetary policy. We find, predictably, that the shock has a contractionary effect on consumption and output in the home economy. The effects of fixed and floating exchange rates are reversed, relative to external balance shocks: when world interest rates go up, it is fixed and not flexible exchange rates that prevent the immediate onset of a contraction.

Turning to unconventional monetary policies, we follow Gertler and Kiyotaki (2010) and analyze recent central bank facilities that provide lending to firms and households (direct lending, in the Gertler-Kiyotaki terminology) or to financial intermediaries (liquidity facilities). The discussion is organized around the following question: suppose that an emerging economy is hit by an external balance shock and that its central bank holds a stock of international reserves (or, equivalently, has access to a credit line abroad in international currency, say dollars). What should the central bank do with those dollars? What unconventional measures, if any, should it undertake?

Three main conclusions emerge. First, direct lending and liquidity facilities make a difference if and only if private sector borrowing constraints bind. This is intuitive, since otherwise the central bank would be offering credit that is no superior to that which domestic agents can already get from private sources abroad.

Second, when borrowing constraints bind, liquidity facilities have a general advantage over direct lending. The intuition follows from the presence of leverage. If loans from the central bank improve the capacity of domestic financial intermediaries to borrow abroad, then a favorable multiplier effect kicks in: for every dollar the central bank lends, the intermediaries can lend more than one dollar to domestic households. Hence, and in contrast with direct lending, financial intermediaries leverage the resources advanced to them by the monetary authority. In a situation of constrained borrowing this is highly beneficial.

Third, the feasibility of direct lending and liquidity facilities is limited by the stock of foreign exchange reserves at the central bank. This is because, ultimately, such policies work by alleviating the external debt constraint. The 
question of optimal accumulation and use of reserves in a dynamic context emerges as a central issue (but we do not tackle it here).

Several other unconventional policies turn out to be similar or even completely isomorphic to direct lending or liquidity facilities. This is the case, specifically, of central bank purchases of banks' equity: we show that the impact of such policies depends crucially on how equity held by the central bank equity affects the borrowing constraint of the banking sector, which in turn reflects how foreign lenders evaluate central bank equity vis a vis privately-held equity. Indeed, if the two kinds of equity are treated in the same way by foreign creditors, equity injections are equivalent to liquidity facilities.

How do conventional and unconventional policies compare with each other? Our analysis suggests that, especially in dealing with external balance shocks, conventional policies can be helpful. But they have limited effectiveness, in the sense that they always involve trade-offs and are useless in relaxing binding financial constraints. In contrast, unconventional policies can offset external balance shocks directly. Yet they are also restricted in a way that conventional policies are not: the amount of relevant central bank lending cannot exceed available foreign exchange reserves (or foreign credit lines), because the central bank cannot create international liquidity. This is a crucial difference between central banks in advanced countries (that can create such liquidity at will) and emerging economies.

Finally, we study sterilized foreign exchange intervention. In our analysis, sterilized intervention can be understood as an unconventional attempt at alleviating the effects of financial constraints. Intervention is effective if and only if financial constraints bind. And, that case, sterilized foreign exchange operations are equivalent to increases in central bank credit, either to households or banks. A corollary is that sterilized intervention can matter only because of the central bank credit required to sterilize, through which the central bank makes its foreign liquidity available to private agents.

This explanation for the real effects of sterilized intervention falls out directly from our analysis, and deserves special mention for at least two reasons. From the point of view of theory, it is new and different from others in the literature, such as those based on portfolio balance or signaling effects. From the point of view of policy, it may help explain why central banks are prone to exchange market intervention at times of financial stress.

The paper is organized as follows. Section 2 describes the model. We define equilibria and characterize steady states in section 3 . Section 4 dis- 
cusses dynamic adjustment to external balance shocks under flexible prices. Adding nominal price rigidity, section 5 focuses on conventional monetary policy. Unconventional policies are the subject of section 6. Section 7 expands on sterilized foreign exchange intervention. Section 8 discusses the implications of an increase in the world rate of interest. Section 9 concludes with additional observations and suggestions for future research. Some peripheral technical derivations are delayed to an appendix.

\section{The Model}

We study a small open economy inhabited by households, firms, and financial intermediaries or "banks" for short. To smooth consumption, households borrow from banks, which in turn borrow from the rest of the world. Because of financial frictions, the external debt of the banks is limited by their equity capital. In turn, households acquire equity in banks subject to an exogenous limit that captures domestic financial frictions: that limit, or equity constraint for short, implies that domestic loan rates rise above the world interest rate in order to match scarce loans with the credit demands of households. There is an economy-wide endogenous collateral constraint, with interesting implications for dynamics and policy.

\subsection{Commodities and Production}

Time is discrete and indexed by $t=0,1,2, \ldots$ There are two traded goods, home and foreign. The foreign good has an exogenous price of one in terms of a world currency, or "dollar". We can therefore talk about foreign goods or dollars interchangeably.

In order to allow for nominal rigidities and a role for monetary policy, we assume that the home good is the usual Dixit-Stiglitz aggregate of varieties, with elasticity of substitution $\epsilon>1$. Each variety is produced by one of a large number of monopolistically competitive firms, via a linear technology in which a unit of domestic labor yields a unit of output. Each variety producer takes wages as given and sets prices, in terms of domestic currency ("peso"), one period in advance. Standard markup pricing then yields $P_{h, t}=W_{t} /(1-$ $1 / \epsilon)$, where $W_{t}$ is the wage and $P_{h, t}$ the price of the domestic aggregate, both in pesos.

We assume the Law of One Price. Then, letting $E_{t}$ denote the nominal 
exchange rate (number of pesos per dollar), the world relative price of the domestic aggregate, or real exchange rate, is

$$
e_{t} \equiv \frac{E_{t}}{P_{h, t}}
$$

With this definition the optimal markup condition becomes

$$
w_{t}=\left(\frac{\epsilon}{\epsilon-1}\right) e_{t}^{-(1-\alpha)}
$$

where $w_{t}=W_{t} / P_{t}$ is the real wage.

Foreign demand for the domestic good is a function $x e_{t}^{\chi}$ of its relative price, with $x$ a shift coefficient and $\chi$ a positive elasticity parameter. Domestic demand, on the other hand, is derived from the demand for overall consumption. Consumption is a Cobb Douglas aggregate of the home aggregate and foreign goods so that, under usual assumptions, its price (the CPI) is $P_{t}=P_{h, t}^{\alpha} E_{t}^{1-\alpha}$. The demand for the home aggregate is then

$$
c_{h, t}=\frac{\alpha P_{t}}{P_{h, t}} c_{t}=\alpha e_{t}^{1-\alpha} c_{t}
$$

where $c_{t}$ is total consumption demand.

The market-clearing condition for home output is

$$
y_{t}=\alpha e_{t}^{(1-\alpha)} c_{t}+x e_{t}^{\chi},
$$

so that total output demand is split between domestic consumption demand and exports.

\section{$2.2 \quad$ Banks}

Domestic households cannot borrow nor lend directly in the world market. Instead, they do so from a large number of domestic financial intermediaries or banks. Banks, in turn, can obtain funding from foreigners, possibly subject to financial frictions.

The representative bank lives for only one period. A typical bank starts a period $t$ with some capital or net worth of $k_{t}$ dollars which, as we will see shortly, is transferred from the households to the banks at the beginning of the period. It is probably best to think of $k_{t}$ as equity sold to households in 
exchange for an equiproportional share of the bank's profits. Alternatively, one can think of $k_{t}$ as deposits in the domestic banking system. The bank can also borrow $d_{t}$ dollars from foreigners, at a fixed interest rate of $\rho \geq 0$. Accordingly, the bank can issue domestic loans worth $l_{t}$ dollars subject to

$$
l_{t}=k_{t}+d_{t}
$$

The bank's mandate is to maximize profits, given by

$$
\pi_{t}=\left(1+\varrho_{t}\right) l_{t}-(1+\rho) k_{t},
$$

where $\varrho_{t}$ is the rate of interest on domestic bank loans between periods $t$ and $t+1$. Banks are competitive and take interest rates as given. ${ }^{4}$

The representative bank is subject to a collateral assumption of the form

$$
d_{t} \leq \theta k_{t}
$$

where $\theta$ is a constant between zero and one. One can rationalize this constraint in various ways. For example, it may reflect the temptation that after borrowing $d_{t}$ the banker can "run away", and take with him an amount equal to $\theta$ times equity. So naturally the banker's debt cannot exceed $\theta k_{t}$.

The constraint can be rewritten as

$$
l_{t} \leq(1+\theta) k_{t}
$$

This emphasizes leverage: it says that the bank can lend up to a multiple $(1+$ $\theta$ ) of its equity. Note also that a bank's profit $\pi_{t}$ can be written as the sum of a "normal" return on its equity plus an excess return on loans:

$$
\pi_{t}=(1+\rho) k_{t}+\left(\varrho_{t}-\rho\right) l_{t}
$$

Excess returns are non-zero only if if $\varrho_{t}>\rho$-that is, if the rate of return on loans exceeds the world interest rate, which is the bank's cost of foreign finance.

Hence the bank's problem has an easy solution. If $\varrho_{t}=\rho$, there are no supra-normal returns, so $l_{t}$ and $d_{t}$ are indeterminate as long as

$$
l_{t}=k_{t}+d_{t} \leq(1+\theta) k_{t}
$$

\footnotetext{
${ }^{4}$ Note that we are allowing for $k_{t}>l_{t}$, i.e. for $d_{t}$ to be negative. If so, the interpretation is that the bank invests excess funds abroad at rate $\rho$.
} 
and $\pi_{t}=(1+\rho) k_{t}$.

In contrast, if $\varrho_{t}>\rho$, the bank will lend as much as it can. The collateral constraint must then bind. Loan volume $l_{t}$ is then given by $(1+\theta) k_{t}$ and the bank's foreign debt is $d_{t}=\theta k_{t}$.

Finally, note that the return to equity will be given by $\pi_{t} / k_{t}$, which can be rewritten as

$$
(1+\rho)+\left(\varrho_{t}-\rho\right)(1+\theta) \equiv\left(1+\omega_{t}\right)(1+\rho)
$$

\subsection{Households}

Domestic households choose how much to consume and work. They also borrow from banks at rate $\varrho_{t}$ and choose how much equity $k_{t}$ to send to banks, collecting the return on that investment next period. Finally, they can invest in a government bond that pays interest $r_{t}$ in terms of the final consumption good. The government bond is in zero net supply, but introducing it allows us to define an interest rate that will be a main lever of monetary policy.

The representative household maximizes

$$
\sum_{t=0}^{\infty} \beta^{t} U\left(c_{t}, n_{t}\right)=\sum_{t=0}^{\infty} \beta^{t}\left[\log \left(c_{t}\right)-\frac{\eta}{2} n^{2}\right]
$$

subject to the sequence of budget constraints (expressed in dollars)

$e_{t}^{-\alpha} b_{t}+k_{t}-l_{t}=\left(1+r_{t-1}\right) e_{t}^{-\alpha} b_{t-1}+\left(1+\omega_{t-1}\right)(1+\rho) k_{t-1}-\left(1+\varrho_{t-1}\right) l_{t-1}+e_{t}^{-\alpha}\left(w_{t} n_{t}+v_{t}\right)+z-e_{t}^{-\alpha} c_{t}$,

where $0<\beta<1, \eta>0, v_{t}$ denotes profits from domestic firms and $z$ is an exogenous endowment of foreign goods (dollars), which we can interpret as oil or another commodity (this will prove useful later when we examine the dynamics of adjustment).

The household's utility function is admittedly restrictive, but most of what follows can be generalized if the period utility is of the form $u(c)-v(n)$, with $u($.$) and v($.$) satisfying usual properties. A more crucial assumption is$ that there is an exogenous limit to the amount of bank equity that the typical household can hold, so

$$
k_{t} \leq \widetilde{k}
$$

where $\widetilde{k}>0$ is some constant. This domestic equity constraint is the result of unmodeled domestic distortions. It could, for example, capture agency 
problems between households and firms, or imperfections in domestic equity markets.

The appendix discusses the solution to the households' dynamic problem. It can be summarized by an optimal labor supply condition

$$
\left(1-\epsilon^{-1}\right) e_{t}^{-(1-\alpha)} c_{t}^{-1}=\eta y_{t},
$$

the consumption Euler equation

$$
c_{t+1}=c_{t} \beta\left(1+r_{t}\right)
$$

and the arbitrage equation

$$
1+r_{t}=\left(1+\varrho_{t}\right)\left(\frac{e_{t+1}}{e_{t}}\right)^{\alpha},
$$

all of which are standard and have intuitive interpretations.

Finally, the appendix shows that the equity constraint must be binding if $\varrho_{t}>\rho$. If the equity constraint is binding, the bank's external debt constraint must also bind; correspondingly, the latter constraint is slack if the former one is. Without loss of generality, then, we impose below that $k_{t}=\tilde{k}$ always, while the constraint $d_{t} \leq \theta k_{t}=\theta \tilde{k}$ will be binding if $\varrho_{t}>\rho$ and slack if $\varrho_{t}=\rho$. And we will say that the economy is constrained in period $t$ if $\varrho_{t}>\rho$, and unconstrained if $\varrho_{t}=\rho$.

\section{$3 \quad$ Equilibrium and steady states}

In this section we first lay out the equilibrium conditions of this model and then analyze different types of steady states.

\subsection{Equilibrium conditions}

In equilibrium, the household budget constraint reduces to

$$
e_{t}^{-\alpha} c_{t}-d_{t}=-(1+\rho) d_{t-1}+e_{t}^{-1} y_{t}+z .
$$

And, as discussed, the equilibrium amount of external debt is limited by the equity constraint, with complementary slackness:

$$
\begin{array}{rlr}
0 \leq d_{t} \leq \theta \widetilde{k} & \text { if } & \varrho_{t}=\rho \\
d_{t}=\theta \widetilde{k} & \text { if } & \varrho_{t}>\rho
\end{array}
$$


A perfect foresight equilibrium is given by sequences $c_{t}, y_{t}, e_{t} r_{t}, \varrho_{t}, d_{t}$ that satisfy (1), (7)-(12) for all $t=0,1,2, \ldots$. This definition assumes that $d_{-1}$ is given and that shocks are absent. The consequences of unexpected shocks are discussed below in the usual way.

It is useful to note that inserting (1) into (10) and simplifying, the latter equation can be rewritten as

$$
(1-\alpha) e_{t}^{-\alpha} c_{t}-\left[z+x e_{t}^{\chi-1}\right]=d_{t}-(1+\rho) d_{t-1}
$$

This equation shows the economy's external balance in dollars and has an intuitive interpretation. The LHS is the trade balance, given by the difference between the dollar value of imports and exports. The RHS expresses that a trade imbalance must be matched by taking new debt over and above the service of the existing debt. A crucial part of what follows is that, in a financially constrained economy, the RHS is largely exogenous, so adjustment to adverse shocks require an immediate fall in imports or an increase in exports, hence some combination of falling consumption and real depreciation.

\subsection{Steady States}

For the rest of the paper, we restrict attention to constrained steady states. The alternative assumption of an unconstrained steady state is not much harder but is somewhat cumbersome, is a knife-edge case, and adds little to our analysis.

We characterize steady states in the usual way. Steady-state variables are identified with an overbar. That a steady state is constrained means that $\bar{\varrho}>\rho$, which in turn implies $\bar{k}=\widetilde{k}$. The Euler condition and interest parity then imply that

$$
1+\bar{r}=1+\bar{\varrho}=\beta^{-1} .
$$

Therefore, a necessary condition for a constrained steady state is that $\beta(1+$ $\rho)<1$.

As discussed, in a constrained steady state the household's equity constraint binds. The external debt constraint correspondingly binds, reflecting the economy's inability of the economy to transfer enough "international collateral" to the banks, which are the only agents that can borrow abroad. In a constrained steady state, the bank's debt is $\bar{d}=\theta \widetilde{k}$-not indeterminate, but a multiple of the equity bound $\widetilde{k}$. The steady state stock of debt only depends on $\theta$ and $\widetilde{k}$. 
In steady state, the economy's budget constraint becomes

$$
\bar{c}=-\bar{e}^{\alpha} \rho \bar{d}+\bar{e}^{-(1-\alpha)} \bar{y}+\bar{e}^{\alpha} z,
$$

the output supply function

$$
\left(1-\epsilon^{-1}\right) \bar{e}^{-(1-\alpha)} \bar{c}^{-1}=\eta \bar{y},
$$

and the market clearing condition

$$
\bar{y}=\alpha \bar{e}^{(1-\alpha)} \bar{c}+x \bar{e}^{\chi} .
$$

Since $\bar{d}=\theta \widetilde{k}$, these three equations determine $\bar{c}, \bar{e}$, and $\bar{y}$. Note that they depend on the debt only through the term $\rho \bar{d}$ in the first equation. An increase in the equity bound $\widetilde{k}$, in particular, implies that the debt will be larger. If $\rho>0$, the economy needs to generate a larger trade surplus every period to service the debt. This requires consumption to be smaller or the real exchange rate to be more depreciated. The interpretation is that the economy is more impatient than the rest of the world, so a permanent increase in $\widetilde{k}$ allows for the banks to borrow more. In equilibrium, this means consumption increases in the short run but falls in the long run.

A special case to which we will pay special attention is $\rho=0$. Then the preceding equations do not depend on debt nor the equity bound $\widetilde{k}$. On the other hand, the external debt $\bar{d}$ and the quantity of bank loans do depend on that bound.

\section{Short Term Adjustment with Flexible Prices}

To highlight the basic workings of the model and the crucial role of financial frictions, this section studies short term adjustment under flexible prices; nominal rigidities and the implications for policy are deferred to later sections. As mentioned, we assume that $\beta(1+\rho)<1$, so that the steady state is constrained.

\subsection{External Balance Shocks: Real and Financial}

Consider three kinds of shocks. The first two are financial in nature: a fall in the commercial bank's debt constraint parameter $\theta$ to $\theta^{\prime}<\theta$, or a drop the 
equity bound, from $\widetilde{k}$ to $\widetilde{k}^{\prime}<\widetilde{k}$. We assume that the shocks are unanticipated and, for concreteness and simplicity, permanent. The two shocks will have a similar impact and call for deleveraging. But they are different in nature. The fall in $\theta$ can be regarded as an external event, equivalent to the "sudden stop" and "reversal of capital flows" discussed by Dornbusch and Werner (1994) and Calvo (1998), and to the "deleveraging shock" discussed by Krugman and Eggertson (2012). The fall in $\tilde{k}$, on the other hand, has been mostly ignored in the literature, but realistically captures domestic distortions that impede the capitalization of the banking system.

The third shock is an unexpected, temporary fall in $z$. In particular, assume that $z$ is constant, except that in some period it falls unexpectedly to $z^{\prime}<z$ for that period only. An unconstrained economy would normally borrow abroad to smooth the effects of this shock. But with a binding borrowing constraint, the pattern of adjustment will be very different.

These three shocks are different but, because the economy is constrained, have the same effects: they all tighten the external balance constraint in the period of the shock. In this sense, they can all be referred to as external balance shocks, and require for an immediate cut in domestic consumption and/or a real devaluation.

To see this formally, assume for simplicity that $\rho=0$, so that these shocks do not change the long run resting position of the economy. Denote the new steady state by overbars. Then $\bar{d}=\theta^{\prime} \bar{k}^{\prime}$, but other steady state variables are unchanged.

Transition to the new steady state must take only one period. We use $c, e, y$, etc. to denote values during that period, which is the period of the shock. The pattern of adjustment is driven by the external balance condition (13), which can be rewritten as:

$$
(1-\alpha) e^{-\alpha} c-\left(x e^{\chi-1}+z\right)=s,
$$

where $s \equiv \tilde{k}^{\prime}\left(\theta^{\prime}-\theta\right)+\theta\left(\widetilde{k^{\prime}}-\widetilde{k}\right)+\left(z^{\prime}-z\right)<0$ is a composite of the external balance shocks. The expression is intuitive and describes how external balance shocks necessitate a reduction of the trade deficit. This is clearly the case if $z$ falls. But in a financially constrained economy, the trade deficit must also fall in response to financial shocks.

Financial constraints can, in fact, amplify the size of the needed adjustment on impact. This is clearly the case of the fall in exports, from $z$ to $z^{\prime}$. In a financially unconstrained economy, the trade deficit would fall in the period of the shock, but the economy would also spread the cost of adjustment 
over time by borrowing in the world market, increasing foreign debt. Here, financial constraints prevent further borrowing, and hence the trade deficit must shrink immediately fully to compensate for the fall in exports. In the case of financial shocks, external balance directly implies that the foreign debt must fall and the trade deficit must shrink on impact. This is necessary because financial constraints bind and the debt is at its upper bound, so it must fall from $\theta \widetilde{k}$ to $\theta^{\prime} \widetilde{k^{\prime}}$.

The external balance condition (17) can be seen as a locus of the combinations $(c, e)$ that are consistent with external adjustment to the shock $s$. In other words, the condition implies that the shock must be met with a reduction in the trade deficit, which requires some combination of a fall in consumption and a real depreciation (an increase in $e$ ). The exact combination is pinned down by the other equilibrium conditions. With flexible prices, the relevant conditions are the optimal labor supply condition (7) and the market clearing condition (1). In the presence of nominal rigidities, as in later sections, the optimal labor supply condition does not hold ex post, and it is replaced by a condition determined by monetary policy.

Once the short term values of $c$ and $e$ are determined in the manner just described, output and labor supply are given by demand, that is (1). The response of output is ambiguous in principle, since consumption falls but real depreciation switches demand towards domestic produce. In our case, however, the latter effect dominates and output must increase under flexible prices, as long as $s<z$ (which must be the case unless the financial shock is too large relative to $z$ ). This is shown in the appendix, with also discusses more formally some of the assertions of this subsection.

Finally, the loan rate adjusts to clear the domestic credit market in the short run, according to:

$$
\bar{c}=c \beta(1+\varrho)\left(\frac{\bar{e}}{e}\right)^{\alpha}
$$

This says that the loan rate (and the spread between it and the international rate $\rho$ ) increases when consumption falls or the real exchange rate depreciates. Recalling that an adverse shock $s$ must result in a combination of falling $c$ and higher $e$, it follows that the shock must increase the loan rate. This is natural: in the face of the shock, households would like to smooth out the adjustment by borrowing; but the economy cannot come up with the necessary funds (on the contrary, deleveraging is necessary). The domestic loan rate must then increase to choke off this increased demand for loans. 


\subsection{Favorable Shocks}

The nonlinearities in the model raise the possibility that financial constraints may be slack in the adjustment to a favorable shock which calls for a reduction in external debt. To see this, consider a temporary increase in exports from $z$ to $z^{\prime}>z$. Intuitively, the economy would like to increase savings to propagate the beneficial impact of the shock to future periods. On the other hand, we know that the steady state does not change.

The adjustment must be as follows: suppose that the economy reaches the steady state one period after the shock (this will be the case if the shock is small enough, as we will see). Then, the three last equations of the last subsection, with $s=z^{\prime}-z>0$, determine $c, y$, and $e$. Therefore consumption must increase, the exchange rate must appreciate, and output must fall on impact. The loan rate $\varrho$ must fall below its steady state value. This is just the reverse of our argument at the end of the previous subsection.

But $\varrho$ cannot drop too much - that is, it cannot fall below $\rho$. This means that if the increase in $z^{\prime}$ is large enough, the economy cannot remain financially constrained in the period of the shock, and therefore $\varrho=\rho$. By the same reasoning, debt must fall below $\theta \widetilde{k}$ in the short run.

To be more precise: there must be a value of $z^{\prime}$, call it $z^{1}$, such the economy ceases to be financially constrained. For such a value, $\varrho=\rho$, and the Euler equation becomes

$$
\bar{c}=c(1+\rho) \beta\left(\frac{\bar{e}}{e}\right)^{\alpha}
$$

This and

$$
\begin{gathered}
\left(1-\epsilon^{-1}\right) e^{-(1-\alpha)} c^{-1}=\eta y, \\
y=\alpha e^{(1-\alpha)} c+x e^{\chi},
\end{gathered}
$$

determine $c, y$, and $e$. Given these values, $z^{1}$ must then be pinned down by the external constraint:

$$
e^{1-\alpha} c=y+e z^{1}
$$

So if the shock is small enough, in the sense that $z^{\prime} \leq z^{1}$, the economy remains financially constrained and converges to the new steady state in one period.

What happens if the shock is larger, so that $z^{\prime}>z^{1}$ ? Clearly, the external debt carried to the period after the shock must be less than its steady state level, so the economy must take at least two periods to converge to the 
steady state. The same reasoning as above suggests that there must be a $z^{2}>z^{1}$ such that, if $z^{\prime} \in\left(z^{1}, z^{2}\right)$, the economy goes back to the steady state after two periods. In this case, the economy is unconstrained in the period of the shock but constrained thereafter; the loan rate rises in the period after the shock to some value higher than $\rho$ but lower than its steady state level. In that period, consumption and the real exchange rate start converging towards their steady state values. Two periods after the shock, the initial debt reduction is completely reversed, and the economy settles back in the steady state.

For even greater values of $z^{\prime}$, adjustment to the steady state can take successively three periods, four periods, etc. Note the contrast with negative shocks, which cause an abrupt adjustment, involving a move to the steady state after only one period, regardless of the size of the shock.

\section{Conventional Monetary Policy}

To study monetary policy, we assume now that prices are fixed one period in advance. With nominal rigidities, the optimal labor supply condition (7) does not hold ex post. What replaces it? We take the view that the monetary authority can control one of the short-term real variables in the model by an appropriate setting of available instruments, although we do not model the specific link between instruments and real variables. ${ }^{5}$

The monetary and exchange rate policy regime makes a crucial difference, so we analyze two alternatives: an exchange rate peg in which the central bank fixes the real exchange rate at its steady state level $\bar{e}$, and a floating exchange rate regime in which the real interest rate is held at its steady state level by central bank policy.

\subsection{External shocks under an exchange rate peg.}

To make the analysis as simple as possible, focus on the case of a constrained steady state in which $\rho=0$, so that consumption, output and the real exchange rate are independent of debt levels. Suppose first that the central bank pegs the real exchange rate at its steady state level $\bar{e}$. Then, consider an unanticipated, adverse external balance shock $s$ of the kind discussed in the previous section.

\footnotetext{
${ }^{5}$ In this we follow e.g. Romer (2013).
} 
Keeping the same notation as before, variables in the period of the shock have no subscript or overbar, while steady-state variables carry an overbar. Since policy keeps $e$ at $\bar{e}$, consumption and output must fall. This is because the external balance constraint (17) becomes

$$
(1-\alpha) \bar{e}^{-\alpha} c-\left(z+x \bar{e}^{\chi-1}\right)=s
$$

As stressed in the previous section, the shock requires a reduction in the trade deficit. But because the exchange rate is fixed, the trade deficit can only fall if consumption falls. Consumption must, in fact, contract more than under flexible prices, since exchange rates cannot aid in the adjustment.

In turn, since output is determined by demand, we have $y=\alpha \bar{e}^{(1-\alpha)} c+$ $x \bar{e}^{\chi}$, so that output falls unambiguously along with the fall in consumption. It is easy to show that the loan interest rate rises, and by more than it would under flexible prices. This is intuitive, because the exchange rate peg requires a sharper consumption fall than under flexible prices, and therefore the demand for loans increases by more.

In summary, the combination of price stickiness and a binding borrowing constraint produce an abrupt adjustment in which consumption and output fall sharply (more than under flexible prices), and the domestic interest rate spikes up.

\subsection{External shocks under an interest rate peg}

Alternatively, suppose that the shock $s$ is the same but monetary policy keeps the real interest rate at its steady state value $1+\bar{r}=\beta^{-1}$. The Euler condition implies that, in the period of the shock, the interest rate peg implies that consumption is constant at its steady state value: $c=\bar{c}$. The external balance equation therefore becomes

$$
(1-\alpha) e^{-\alpha} \bar{c}-\left(z+x e^{\chi-1}\right)=s
$$

The LHS is a decreasing function of $e$ as long as $\chi$ is larger than one. Therefore (recalling $s$ becomes negative) the shock causes a real depreciation ( $e$ goes up). The intuition, clearly, is that the trade adjustment required by an adverse shock cannot be met by a fall in consumption, which is fixed by the interest rate policy. Instead, the dollar value of imports must fall or exports must increase, both of which are accomplished by a real depreciation. In 
fact, it is easy to see that the real depreciation must be steeper than under flexible prices, since consumption does not help with external adjustment.

In this case the market-clearing condition is:

$$
y=\alpha e^{(1-\alpha)} \bar{c}+x e^{\chi} .
$$

So output increases in response to the shock, since consumption does not move but $e$ is higher than in steady state.

Finally, the arbitrage condition (9) in this case is

$$
1+\bar{r}=(1+\varrho)\left(\frac{\bar{e}}{e}\right)^{a}
$$

Since $e$ rises above $\bar{e}$, the loan rate $\varrho$ increases above its steady state value. This is necessary to keep the real interest rate $\bar{r}$ (which is defined in terms of the consumption aggregate) from falling due to the temporary depreciation.

So under an interest rate peg and a floating exchange rate we have a very different pattern of adjustment than under a fixed exchange rate. As long as export demand is not too price inelastic, a real depreciation raises both the dollar value of exports and the level of output. Consumption is constant, but the dollar value of consumption falls, and so does the dollar value of imports. Both of these factors ensure external adjustment to the shock, even though the economy cannot borrow more in order to smooth out the consequences of the shock.

\subsection{Currency Mismatches}

So far we have assumed that the equity capital made available to banks by households is denominated in foreign currency. But this does not have to be so, nor is it necessarily so in the real world. Alternatively, let us assume that the equity constraint is not $k_{t} \leq \widetilde{k}$, but instead

$$
e_{t}^{\alpha} k_{t} \leq \widetilde{k}
$$

so that implicitly we now assume that the equity capital is denominated in domestic currency. Since foreign and domestic loans are denominated in foreign goods (or dollars), the new assumption captures the possibility of a currency mismatch. This means that as relative prices change, in particular as the real exchange rate depreciates (an increase in $e_{t}$ ), the equity constraint tightens. 
The necessary amendments to the model are straightforward. The bank's problem in subsection (2.2) is untouched, while the household's problem and its solution remains the same except for the obvious correction to the complementarity condition. As a consequence, the definition of equilibrium is the same except that (11)-(12) is replaced by

$$
\begin{gathered}
e_{t}^{\alpha} d_{t} \leq \theta \widetilde{k}, \\
e_{t}^{\alpha} d_{t}=\theta \widetilde{k} \quad \text { if } \quad \varrho_{t}>\rho
\end{gathered}
$$

The analysis of steady states also remains essentially untouched. Focusing in the financially constrained case, (14)-(16) must still hold. These equations depend on $d$, which in this case must satisfy

$$
\bar{e}^{\alpha} \bar{d}=\theta \widetilde{k} .
$$

Hence, if $\rho>0$, the preceding equation plus (14)-(16) simultaneously determine $\bar{y}, \bar{c}, \bar{e}$, and $\bar{d}$. If $\rho=0$, on the other hand, (14)-(16) remain independent of $d$, and hence suffice to pin down $\bar{y}, \bar{c}$, and $\bar{e}$. In this case, $\bar{e}^{\alpha} \bar{d}=\theta \widetilde{k}$ determines $\overline{\mathrm{d}}$.

Now consider the implications of currency mismatches for shocks and alternative monetary policies under prices that are sticky (for one period only). Continue the analysis of an external balance $s$ as before, which we now interpret exclusively as a temporary adverse shock to $z$, the endowment of the foreign good, and ask how the analysis of the preceding two subsections must change. Assume $\rho=0$ for simplicity. Then the old and new steady state values of output, consumption, the real exchange rate, and debt are the same. Let us denote them by $\bar{y}, \bar{c}, \bar{e}, \bar{d}$.

Under afixed exchange ratepolicy, the analysis is just the same as without currency mismatches. This should be evident because a fixed exchange rate eliminates any additional tightening of the equity constraint that would result from a real depreciation. The shock has to be accommodated by a contraction in aggregate demand and output, as before.

With a flexible exchange rate and fixed real interest rate policy, the analysis here is considerably more involved because, given that the shock results in an exchange rate depreciation, the external debt ceiling tightens so that on impact the debt must fall below its steady state level. As a consequence, it is no longer the case that the economy goes back to steady state after just one period. Instead, it turns out that the return to the steady 
state is only asymptotic even if the economy is constrained in every period after the shock.

We can say more, however, assuming that the shock is small enough, so that the economy remains financially constrained in every period. Because of the perfect foresight dynamics starting the period after the shock, consumption after the period of the shock must be a decreasing function of the debt level $d$ determined the period of the shock, with the intuition being that the lower is accumulated debt, the higher consumption can afford to be thereafter. Note also that the fixed interest rate policy implies that consumption in the period of the shock must be the same as consumption one period after (recall the Euler equation). Both must be the same decreasing function of $d$.

What does this mean for the behavior of the real exchange rate? Now the external constraint can be written as

$$
(1-\alpha) c-e^{\alpha}(d-\bar{d})=e^{\alpha} z^{\prime}+x e^{\chi-(1-\alpha)}
$$

This is the same equation as in the case without currency mismatches, except that in that earlier case $c=\bar{c}$ (because of the fixed interest rate policy) and $d=\bar{d}=\theta \widetilde{k}$ (because of the debt constraint), so that the LHS was simply equal to $(1-\alpha) \bar{c}$. In this case, by contrast, the exchange rate depreciation implies that $d<\bar{d}$, which together with the interest rate policy implies that $c>\bar{c}$. Hence the LHS must be greater than $(1-\alpha) \bar{c}$ regardless of the value of $e$, and in fact it must be an increasing function of $e$ ( $\left.\operatorname{since} e^{\alpha} d=\theta \widetilde{k}\right)$. It is then apparent that currency mismatches imply that the shock must result in a steeper depreciation of the currency (see Figure 1). The intuition is simple: the shock tightens the equity constraint, which together with interest rate policy implies that the required external adjustment is larger than without currency mismatches. Hence the exchange rate has to depreciate by more to generate the additional expansion of exports.

The lesson is that currency mismatches add amplification and persistence to shocks, because of the effects of exchange rate movements on financial constraints. Such effects are eliminated under fixed exchange rates, which therefore gain some appeal relative to flexible rates. But, as stressed, fixed exchange rates remain ineffective to prevent an aggregate demand contraction in response to the adverse shocks. 


\subsection{The limits of conventional monetary policy}

We have seen that, in the face of external balance shocks, a floating exchange rate regime that stabilizes the interest rate also manages to keep consumption stable, while at the same time output rises. This result might seem surprising, especially in the presence of foreign currency debt and even of currency mismatches that imply a tighter borrowing constraint.

In that sense, floating exchange rates appear to be more appealing than an exchange rate peg, which is clearly contractionary. But even then, conventional policy remains unsatisfying in this setting. To see why, recall our setup has two distortions. The first one is a monopolistic competition distortion, of the type that is familiar since the pioneering work of Mankiw (1985) and Blanchard and Kiyotaki (1987). This distortion causes underemployment and underproduction, so that the marginal cost of foregoing one dollar of consumption is greater than the marginal cost of the effort to produce one more dollar of output to sell on the world market. The second distortion is a financial constraint which, when binding, prevents domestic agents from borrowing as much as they would like to given prevailing market conditions. This constraint proves particularly onerous when the economy suffers adverse external balance shocks and domestic agents would like to borrow in order to ease adjustment -but cannot.

Conventional monetary policy can help alleviate the first distortion but not the second. It is well understood that, in models in the Mankiw-BlanchardKiyotaki tradition with sticky prices, a surprise monetary expansion or interest rate cut can expand employment and output, taking the economy closer to the first best. Here, in the face of an external balance shock, allowing the exchange rate to depreciate helps expand output and stabilize consumption. Yet the depreciation can do nothing to offset the borrowing constraint - in fact, in the presence of currency mismatches it can make that constraint tighter. That is one reason to explore, as we do below, whether other "unconventional" policies can do better. It will turn out, as we will see, such unconventional policies are most effective precisely when adjustment under conventional policies is "most painful"-that is, when financial constraints bind. ${ }^{6}$

\footnotetext{
${ }^{6}$ With currency mismatches, there may be another reason. We saw that a depreciation causes the equity constraint to tighten, so that in equilibrium a larger depreciation is necessary to restore external equilibrium after a shock. But that is only half the story. The external constraint is now a hump-shaped function of $e$. That is to say, up to a point a real
} 


\section{Unconventional Policies}

Since the global crisis of 2008-09, advanced country central banks have engaged in all sorts of unconventional monetary policies, motivating a lively debate in the academic and the policy literature. Much less studied is the fact that emerging market central bank have also engaged in unconventional, though not always novel, monetary and financial policies.

Prior to the crisis, many emerging market central banks claimed to adhere to inflation-targeting, or a close version. At its simplest, this monetary framework implied using the short domestic interest rate to target some forwardlooking measure of inflation, while letting the exchange rate float. Yet to a limited extent before the crisis, and with abandon after the big crash, most emerging central banks deviated from this simple orthodoxy. They often engaged in foreign exchange intervention, whether sterilized or not. ${ }^{7}$ They also fiddled with reserve requirements in order to control the growth of domestic credit or monetary aggregates. ${ }^{8}$ And as the credit crunch caused by the crisis made itself felt, they did as their developed country counterparts, lending to banks and households, buying bonds and other kinds of paper of different maturities, and sometimes going as far as to take equity positions in domestic financial intermediaries. ${ }^{9}$

Several questions arise. Should we understand such unconventional policies as an attempt to get around the borrowing constraints that play a central role here? If in fact policies do affect financial constraints, what are their effects on macroeconomic variables? And, what if conventional and unconventional policies are applied simultaneously? These are some of the questions

depreciation induces the fall in the trade deficit needed to accommodate the external shock. But beyond that point, further real devaluation is self-defeating, because the adverse effect of depreciation on the equity constraint dominates. Put differently, there is a maximum external adjustment that can be accomplished via real devaluation alone. Moreover, notice that non-monotonicity can occur even in the absence of currency mismatches. In our analysis above we assumed for simplicity that $\chi$, the price elasticity of export demand, was greater than one. But this need not be so. A real devaluation cuts the unit dollar price of exports and at the same time increases export volumes. If $\chi<1$, the first effect is larger than the second, so the total dollar value of exports falls as a result of a devaluation. and, again, there is a maximum external adjustment that can be accomplished via real devaluation alone.

${ }^{7}$ Chang (2007).

${ }^{8}$ Montoro and Moreno (2011).

${ }^{9}$ Céspedes, Chang, and Velasco (2014). 
we study in this section.

\subsection{Direct Lending}

Start the discussion by assuming that the central bank has $f>0$ dollars as foreign exchange reserves. A passive policy might then be to invest them in the foreign exchange market, earning the world rate $\rho$, and to transfer $\rho f$ to households every period.

In the spirit of Gertler and Kiyotaki (2010), we consider an alternative direct lending policy: in period $t$ the central bank lends $l_{t}^{g}$ to households at the market rate $\varrho_{t}$. The amount $l_{t}^{g}$ is a policy decision. We assume that $0 \leq l_{t}^{g} \leq f$, and that the central bank makes a transfer $\tau_{t}$ to the household at the beginning of each period, so as to keep the amount of foreign reserves constant at $f$.

The commercial bank's decision problem is the same as before. The household's problem remains almost unchanged, too, except that the budget constraint is now

$b_{t}+e_{t}^{\alpha}\left(k_{t}-l_{t}^{h}\right)=\left(1+r_{t-1}\right) b_{t-1}+e_{t}^{\alpha}\left(1+\omega_{t-1}\right)(1+\rho) k_{t-1}-e_{t}^{\alpha}\left(1+\varrho_{t-1}\right) l_{t-1}^{h}+w_{t} n_{t}+v_{t}+e_{t}^{\alpha}\left(z+\tau_{t}\right)-c_{t}$,

where $l_{t}^{h}=l_{t}+l_{t}^{g}$ is the sum of bank loans plus central bank loans to the household. Note that the RHS includes the central bank transfer $\tau_{t}$.

The household's first order conditions are exactly as before. But to derive the associated equilibrium, we need to be more explicit about the central bank transfer $\tau_{t}$. As mentioned, at the end of each period $t$, the central bank lends $l_{t}^{g}$ to the household. We assume that the remainder, $f-l_{t}^{g}$, is invested in the world market. In period $t+1$, therefore, the central bank's transfer must be

$$
\tau_{t+1}=\left(1+\varrho_{t}\right) l_{l}^{g}+(1+\rho)\left(f-l_{t}^{g}\right)-f=\rho f+\left(\varrho_{t}-\rho\right) l_{t}^{g}
$$

This amount is the world return on foreign reserves plus the supranormal profit on central bank lending. One can check that, with this assumption, the central bank starts every period with the same amount of reserves. It should also be noted that this is not an innocuous assumption, in the sense that alternative uses of these "quasi-fiscal" profits may change equilibria. 10

\footnotetext{
${ }^{10}$ While not the case in our model, one might conjecture that some central bank lending programs may lead to losses. This would require $\tau$ to be negative; but this may not be
} 
With this and our previous assumptions, it follows that, in equilibrium, the external balance constraint reduces to

$$
(1-\alpha) e_{t}^{-\alpha} c_{t}-\left[x e_{t}^{\chi}+z\right]=\left(d_{t}+l_{t}^{g}\right)-(1+\rho)\left(d_{t-1}+l_{t-1}^{g}\right)+\rho f .
$$

Compare this expression with the original (13). The new form of the external constraint is intuitive: direct lending by the central bank allows the economy to circumvent the external credit limit, at a $\operatorname{cost} \rho$, which is the opportunity cost of reserves to the economy.

The other equilibrium conditions remain exactly the same, so that the path of $l_{t}^{g}$ affects equilibrium only through the immediately preceding external constraint (20). This reveals a crucial aspect of credit policies. Take any equilibrium in which the financial constraint is slack in a period $t$, that is, $0<d_{t}<\theta \widetilde{k}$. Then it is easy to see that, for any alternative values $\hat{d}_{t}, \hat{l}_{t}^{g}$ such that $0<\hat{d}_{t}<\theta \widetilde{k}$ and $d_{t}+l_{t}^{g}=\hat{d}_{t}+\hat{l}_{t}^{g}$, the same equilibrium obtains. (To see this, observe that the equilibrium conditions depend only on the sum $d_{t}+l_{t}^{g}$ and not on $d_{t}$ and $l_{t}^{g}$ separately, as long as $0<d_{t}<\theta \widetilde{k}$.) The intuition is simple: suppose that the financial constraint does not bind in period $t$. Then, if the central bank extends additional credit to the commercial bank, the latter simply reduces its external debt by an offsetting amount, leaving the total supply of loans in the economy unchanged. Since the financial constraint does not bind, the same equilibrium obtains with the loan interest rate equal to the world interest rate.

In other words, the amount of central bank credit in period $t$ is irrelevant if financial constraints do not bind in that period. This is an instance of a more general result, discussed by Céspedes, Chang, and Velasco (2015) and others, which applies to a large set of unconventional monetary policies, including many that have been tried in practice.

To move forward, suppose $l_{t}^{g}$ is a constant, and consider steady states. The external balance constraint (20) becomes

$$
(1-\alpha) \bar{e}^{-\alpha} \bar{c}-\left[x \bar{e}^{\chi-1}+z\right]=-\rho\left(\theta \widetilde{k}+l^{g}\right)+\rho f
$$

the case in which the steady state is financially constrained, so that $\bar{d}=\theta \widetilde{k}$. In steady state, central bank lending allows the economy to effectively borrow more than that limit.

feasible, e.g. if transfers from the taxing authority to the central bank have a limit. These considerations restrict the set of feasible policies. For a thorough discussion, see Benigno and Nistico (2015). 
The case $\rho=0$ is instructive. Then, as before, the steady state is independent of $d$ and of $l^{g}$. But direct lending matters in the short run: the external constraint can be rearranged to read

$$
(1-\alpha) e_{t}^{-\alpha} c_{t}-\left[x e_{t}^{\chi}+\widehat{z}\right]=d_{t}-d_{t-1}
$$

where

$$
\hat{z}_{t}=z+l_{t}^{g}-l_{t-1}^{g} .
$$

In this case, central bank credit is isomorphic to control of $z$. Notice it is the change in $l_{t}^{g}$, not the level, that matters. If $l_{t}^{g}$ is constant, the policy is irrelevant. This is intuitive, since $z$ is a flow variable, while $l_{t}^{g}$ is a stock variable. Notice also that if $f$ is large enough relative to the size of the shock, this policy can be used to offset completely a temporary fall in $z$ or other equivalent shocks.

To sharpen intuition consider, in particular, a temporary fall in $z$. Normally (without borrowing constraints), the household would like to borrow abroad in order to smooth out the consumption effects of the temporary shock. If the real international interest rate is positive, so that borrowing is costly, the new feasible level of consumption has to adjust downward to reflect the carrying cost of the additional debt. But if, as we have assumed here, $\rho=0$, so the additional debt has no carrying cost, the level of consumption can afford to remain the same it would have been without the shock.

Note, however, two related aspects of the policy: we have assumed that the increase in credit, $l_{t}^{g}-l_{t-1}^{g}$, is permanent; and we have assumed that $l_{t}^{g} \leq f$ or, equivalently, that the credit increase is no more than the available amount of reserves, given by $f-l_{t-1}^{g}$. This implies that a credit increase to offset a temporary fall in $z$ will not be feasible if $f-l_{t-1}^{g}$ is small. This would be the case if $f$ is small, but also if $l_{t-1}^{g}$ is large, due to analogous credit operations in the past.

In other words, a main lesson is that direct lending can be used to offset directly external balance shocks, but it is limited by foreign exchange reserves. The question of appropriate reserves accumulation and how it limits credit policies then emerges as a critical one. Further progress would require to examine settings in which, realistically, $z$ is continuously buffeted by shocks, instead of the one time shocks we have allow for in this paper. 


\subsection{Liquidity Facilities}

Suppose that, instead of lending to households, the central bank lends part or all of its $f$ resources to banks. This is akin to what Gertler and Kiyotaki (2010) term liquidity facilities, or discount-window lending.

Such lending alters the bank's problem. The amount that the bank can lend is now

$$
l_{t}=k_{t}+d_{t}+d_{t}^{g},
$$

where $d_{t}^{g}$ is the loan from the central bank. We assume that central bank loans carry the world rate of interest, and that the size of $d_{t}^{g}$ is determined by policy, subject to $0 \leq d_{t}^{g} \leq f$.

The impact on the bank's incentive constraint turns out to be key. We assume that discount lending affects the commercial bank's foreign debt limit in the following way:

$$
d_{t} \leq \theta k_{t}+\phi d_{t}^{g}
$$

with $0 \leq \phi \leq 1$. The idea is that a banker can "abscond" after obtaining external credit $d_{t}$, as before, but now the cost is not only a fraction $\theta$ of equity but also a fraction $\phi$ of its debt to the central bank. If $\phi=1$, in particular, the assumption is that the banker cannot cheat on the central bank.

Combining the two expressions, the associated limit on bank loans is now

$$
l_{t} \leq(1+\theta) k_{t}+(1+\phi) d_{t}^{g} .
$$

This emphasizes that, if $\phi>0$, using central bank liquidity facilities banks can leverage up and multiply $d_{t}^{g}$ in the world market. In this sense, lending to banks delivers more bang for the buck than lending to households, just like an increase in private equity. The crucial assumption, of course, is that the existence of a central bank loan increases the cost to the bank of reneging on its foreign debt.

The commercial bank now chooses $l_{t}$ and $d_{t}$ to maximize profits, given by

$$
\pi_{t}=\left(1+\varrho_{t}\right) l_{t}-(1+\rho)\left(d_{t}+d_{t}^{g}\right)=\left(\varrho_{t}-\rho\right) l_{t}+(1+\rho) k_{t},
$$

as before. Hence the bank's problem has a similar solution as before: if $\varrho_{t}=\rho, l_{t}$ and $d_{t}$ are indeterminate as long as (22) is satisfied; if $\varrho_{t}>\rho$, (22) must hold with equality, so $d_{t}=\theta k_{t}+\phi d_{t}^{g}$.

The household's problem is as before, except that we assume that the central bank transfers the difference between receipts from its past loans 
plus any interest earned on the resources not lent, minus the amount needed for new investments. But because the central bank changes $\rho$ for its credit, the transfer is equal to the world return on foreign reserves:

$$
\tau_{t}=(1+\rho) d_{t-1}^{g}+(1+\rho)\left(f-d_{t-1}^{g}\right)-\left[d_{t}^{g}+\left(f-d_{t}^{g}\right)\right]=\rho f .
$$

With this assumption, the external constraint reduces to

$$
(1-\alpha) e_{t}^{-\alpha} c_{t}-\left[x e_{t}^{\chi-1}+z\right]=\left(d_{t}+d_{t}^{g}\right)-(1+\rho)\left(d_{t-1}+d_{t-1}^{g}\right)+\rho f
$$

which is the same as in the case of the previous subsection, except that $d_{t}^{g}$ replaces $l_{t}^{g}$. In contrast with the direct lending policy, however, the liquidity facility affects the external credit limit, and the bank can now borrow more abroad and lend more to the household.

One implication is that, as with direct lending, the amount of liquidity provided by the central bank $d_{t}^{g}$ does not matter if and only if financial constraints are slack (meaning $0<d_{t}<\theta \tilde{k}+\phi d_{t}^{g}$ in this case). Another implication is that financially constrained steady states are given by

$$
(1-\alpha) \bar{e}^{-\alpha} \bar{c}-[x \bar{e} \chi-1+z]=-\rho\left[\theta \widetilde{k}+(1+\phi) d^{g}\right]+\rho f .
$$

This emphasizes that the liquidity facility is more effective than direct lending in increasing the economy's capacity to borrow abroad. The intuition, again, is leverage.

In the case of $\rho=0$, the external constraint is as in (21), with $\hat{z}_{t}=$ $z+\left(d_{t}^{g}-d_{t-1}^{g}\right)$. This is just as with direct lending. However, the additional consideration is that, if constraints bind so that $\varrho_{t}>\rho, d_{t}=\theta \widetilde{k}+\phi d_{t}^{g}$. To illustrate the differences further, suppose that $\rho=0$ and the economy is in a financially constrained steady state with zero central bank loans (in either direct credit or discount credit). Consider then an unexpected, temporary fall in $z$ to $z^{\prime}<z$. The analysis of the previous subsection implies that the central bank would be able to prevent the shock from affecting real allocations by extending direct credit to households in the amount $l^{g}=z-z^{\prime}$ (this would be possible provided $\left.z-z^{\prime} \leq f\right)$. Alternatively, with a liquidity facility, the amount needed for the same purpose would be $d^{g}=\left(z-z^{\prime}\right) /(1+\phi)$. This is because the liquidity facility would allow commercial banks to borrow an amount $\phi d^{g}$ over and above the original credit limit of $\theta k$. If $\phi>0$, then, the liquidity facility requires fewer resources than direct credit. In fact, if $f<z-z^{\prime} \leq(1+\phi) f$, the former is feasible but the latter is not. ${ }^{11}$

\footnotetext{
${ }^{11}$ Note, in the previous example, that we have assumed that the amount of central bank
} 


\subsection{Equity Injections}

Lending is not the only operation that the central bank can engage in vis à vis the bank. Instead of lending at rate $\rho$, the central bank can choose to take an equity position in the commercial bank. In so doing, the central receives an equi-proportional share of the commercial bank's profits. Under some conditions, the analysis is the same as with liquidity facilities. But it is interesting to see the details, if only to identify the necessary conditions for this operation to play a useful role in offsetting the effects of shocks under financial distortions.

Let $k_{t}^{g}$ denote the central bank equity position in the commercial bank. Then the total equity of the commercial bank is $\kappa_{t}=k_{t}+k_{t}^{g}$. The commercial bank's problem is then exactly as described in subsection (2.2), except that $\kappa_{t}$ replaces $k_{t}$ in all the obvious expressions.

The household's problem is as before, and its solution is the same, except that the budget constraint reduces to

$e_{t}\left(k_{t}-l_{t}\right)=-e_{t}\left(1+\varrho_{t-1}\right) l_{t-1}+e_{t}\left(\frac{k_{t-1}}{\kappa_{t-1}}\right) \pi_{t}+x e_{t}^{\chi}+e_{t} z-(1-\alpha) e_{t}^{(1-\alpha)} c_{t}+e_{t} \tau_{t}$

where the RHS emphasizes that, in equilibrium, the household receives a fraction $k_{t-1} / \kappa_{t-1}$ of the commercial bank's profits, and also a transfer $\tau_{t}$ from the government.

The central bank finances the equity injection using reserves (or, equivalently, a dollar credit line). In each period $t$, the central bank takes an equity position $0 \leq k_{t}^{g} \leq f$ in the commercial bank, and invests $f-k_{t}^{g}$ in the world market. As before, we assume that the central bank transfers its profits to the household, so that

$$
\tau_{t}=\left(\frac{k_{t-1}}{\kappa_{t-1}}\right) \pi_{t}+(1+\rho)\left(f-k_{t-1}^{g}\right)-f=\pi_{t}-(1+\rho) k_{t-1}^{g}+\rho f .
$$

Combining the last two expressions with the definition of profits $\pi_{t}$, and recalling that $l_{t-1}=d_{t-1}+\kappa_{t-1}=d_{t-1}+k_{t-1}+k_{t-1}^{g}$, we have the equilibrium version of the crucial external constraint:

$$
-\left(d_{t}+k_{t}^{g}\right)=-(1+\rho)\left(d_{t-1}+k_{t-1}^{g}\right)+x e_{t}^{\chi-1}+z-(1-\alpha) e_{t}^{-\alpha} c_{t}-\rho f .
$$

credit (either to households or banks) increases permanently. This is for simplicity of exposition: the assumption ensures that the economy returns to the original steady state in the period of the shock. 
In turn, the credit limit is

$$
d_{t} \leq \theta \kappa_{t}=\theta\left(\widetilde{k}+k_{t}^{g}\right)
$$

These expressions are the same as in the previous subsection, except that $k_{t}^{g}$ has replaced $d_{t}^{g}$ and that $\phi=\theta$. The latter fact reflects, of course, our assumption that central bank equity in the commercial bank is treated the same as the household's equity.

The conclusions of the previous subsection then apply, in particular that operations involving banks -whether liquidity lending or equity injectionsare more effective than direct credit in relaxing financial constraints because of the bank's leverage. But our discussion also suggests how equity injections might differ from liquidity facilities. ${ }^{12}$

\subsection{Combining Credit Policy and Monetary Policy}

For monetary policy to have an effect one must assume sticky prices. In that case, as we have seen above, the optimal labor supply condition (7) does not hold ex post in the event of shocks. Instead, monetary policy provides an additional short run condition for equilibrium. In the cases we have examined, this means that either the real exchange rate or the real interest rate are fixed by policy at their steady state levels.

Given these observations, it is not hard to characterize the implications of combining credit policy and monetary policy. Consider, for example, a temporary fall in $z$ to $z^{\prime}<z$ met with an increase of central bank credit to the commercial bank, and assuming either fixed exchange rates or a fixed interest rate policy. As we have seen, the economy converges after one period to the steady state, which under the simplifying assumption $\rho=0$ is independent of the debt and credit policy. Hence, in the period of the shock, the external constraint can be written as

$$
(1-\alpha) e^{-\alpha} c-\left[x e_{t}^{\chi-1}+z\right]=s
$$

\footnotetext{
${ }^{12}$ Gertler and Kiyotaki (2010), for example, suggested that the central bank might pay more than the market price for its equity position. They stressed that this should be understood as a transfer from the central bank from the commercial bank. This is clearly also the case in our framework.
} 
with the external adjustment $s$ is given by

$$
s=(1+\theta g) \Delta d g-\Delta z
$$

where $\Delta z=z-z^{\prime}$ is the fall in exports and $\Delta d$ and $\Delta d^{g}$ denote the increase in external debt and central bank liquidity, respectively, in the period of the shock. The last equality emphasizes that the credit response $\Delta d^{g}$ essentially offsets the shock $\Delta z$ by the amount $\left(1+\theta^{g}\right) \Delta d^{g}$.

The short run equilibrium is determined by the preceding equation together with the domestic market-clearing condition $y=\alpha e^{1-\alpha} c+x e^{\chi}$ and the assumption that $e=\bar{e}$ (under a fixed exchange rate) or $c=\bar{c}$ (under a fixed interest rate).

This all means that the analysis of monetary alternatives complemented by credit policies is as usual, once one takes into account how credit policy effectively reduces the size of the external balance adjustment from $\Delta z$ to $\left(1+\theta^{g}\right) \Delta d^{g}-\Delta z$. Again, a crucial issue is the availability of international reserves, which places an upper bound on $\Delta d^{g}$.

To summarize, in emerging markets unconventional policies can offset exogenous shocks fully but are limited by international reserves. In contrast, monetary policy faces no such limits, but involve tradeoffs involving output, consumption and the real exchange rate, all of them operating through the external balance condition. Further research is warranted in this regard, especially on the optimal accumulation and utilization of foreign reserves in (potentially) financially-constrained open economies.

\section{Sterilized intervention}

Many emerging markets claim to target inflation. A standard version of that policy requires that monetary and interest rate policy be targeted at the rate of inflation, while letting the exchange rate float freely. In that framework there is no direct feedback from the exchange rate back to (say) the policy interest rate. The level of the nominal (and real) exchange rate only matters for policy to the extent that it affects the expected inflation rate and/or the output gap. Moreover, the policy response to movements in the expected inflation rate and the output gap is supposed to involve the interest rate only, excluding by design active intervention in the foreign exchange market.

This theory stands in sharp contrast to what many economies (emerging and also advanced) have actually done during and since the 2008-09 crisis. 
Many have pursued standard foreign exchange intervention, both sterilized and unsterilized. Attempts to affect the exchange rate via the derivatives market have also been common. In Céspedes, Chang and Velasco (2014) we provide an account of such policy responses in Latin America. Similar policies have been put into place in other emerging market economies, particularly in Asia.

In what follows we ask what effects, if any, sterilized foreign exchange intervention has in our model. We deliver one conclusion up front: such intervention has effects if and only borrowing constraints bind. In this sense, foreign exchange intervention can be understood as an "unconventional" attempt to lessen the effects of such borowing constraints.

When discussing sterilized foreign exchange intervention, it is necessary to add to the model some view on the supply and demand of domestic money. The specific details are not important: one could append a quantity equation or one could assume that domestic money is in the household's utility or production function; there are other, well-known alternatives. For concreteness and simplicity also, we suppose for the rest of this subsection that money exogenous, so that equilibrium in the money market only determines the price level (the argument is modified in an straightforward way if the price level is determined in alternative ways, such as interest rate rules, and money market equilibrium determines the equilibrium money stock endogenously).

Consider the impact of a sterilized central bank purchase of one dollar with domestic currency. Without sterilization, nominal money supply $M_{t}$ would increase by $E_{t}$ (the nominal exchange rate); central bank foreign reserves would correspondingly increase by one dollar. However, sterilization means that the central bank must adjust its asset position so as to keep $M_{t}$ the same. To do this, in particular, the central bank can increase its credit to either households or commercial banks by the equivalent of one dollar (it does not matter here if such an increase is given in domestic currency or foreign currency, as households or banks can rearrange their currency holdings accordingly). The net result, in this case, is that at the end of the process $M_{t}$ will not have changed, central bank foreign reserves will have fallen by one dollar, and either $l_{t}^{g}$ or $d_{t}^{g}$ will have increased by one dollar.

Hence foreign exchange intervention affects the equilibrium conditions only through their effect on $l_{t}^{g}$ or $d_{t}^{g}$. While this argument is simple, it has significant implications for our views of sterilized foreign exchange intervention. We have discussed the issue at length in Céspedes, Chang and Velasco (2013), in the context of another model that also involves financial 
constraints. Using the model here, one can easily show that:

- Sterilized foreign exchange operations are equivalent to increases in central bank credit, either to households or banks.

- Such operations matter only because of the central bank credit required to sterilize, through which the central bank makes its foreign liquidity available to private agents.

- Sterilized foreign exchange intervention matters only when financial constraints are binding. Under other circumstances, as we have seen in earlier sections, central bank credit, either to households or banks, has no real effects.

From the point of view of theory, these arguments for the real effects of sterilized intervention are new and independent of others in the literature, such as portfolio balance effects or signaling effects. From the point of view of policy, they help explain why central banks are prone to intervention at times of financial stress, precisely when borrowing constraints bind. More broadly, if financial crisis involve a scarcity of liquidity, and in our perspective exchange market intervention is precisely a means for providing liquidity, it is only natural that monetary authorities will display what Calvo and Reinhart (1999) termed "fear of floating", in the sense of keep in intervention among the policy tools to be used in times of stress.

\section{Increases in the World Interest Rate}

This section briefly considers an increase in the world interest rate $\rho$. This is obviously of interest given prospective changes in monetary policy in advanced nations, which could have important effects on emerging markets, as well as the ongoing debate on the long run world interest rate.

\subsection{Impact on Steady State}

Consider first a permanent increase in the world interest rate from $\rho$ to $\rho^{\prime}>\rho$, starting from a constrained steady state. ${ }^{13}$ As before, we denote the resulting (new) steady state with overbars.

\footnotetext{
${ }^{13}$ It is not hard to show that assuming that the increase in $\rho$ is transitory only introduces additional dynamics, which we omit to save space.
} 
Because the steady state is constrained, the stock of steady state debt remains the same: $\bar{d}=\theta \tilde{k}$. The new steady state values of consumption, output, and the real exchange rate are then given by equations (14)-(16), except that $\rho^{\prime}$ replaces $\rho$ in (14). It is straightforward to show that, relative to the old steady state, consumption is lower, output is higher, and the real exchange rate more depreciated. This reflects that a higher interest rate requires higher debt service, which must be met with an increase in the trade surplus.

\subsection{Adjustment under Flexible Prices}

For simplicity only, we assume that $\rho=0$ initially. Assume also that the economy remains constrained in every period. Then the external balance condition in the period of the shock becomes

$$
(1-\alpha) e^{-\alpha} c=z+x e^{\chi-1}
$$

because debt remains unchanged at $\bar{d}$. (As before, $c, y$, and $e$ refer to values in the period of the shock).

The preceding equation, market-clearing condition for home output (1), and labor supply condition (7) now determine $c, y$ and $e$. But these are the same equations that pin down the old steady state, so $c, y$ and $e$ must be unchanged at their old steady state values. Adjustment, when it occurs, is therefore abrupt: the economy remains in the old steady state in the period of the shock, and jumps to its new state one period after.

We have assumed that the economy remains financially constrained in all periods. But this need not be so if the shock is large enough. To see this, recall that the interest rate $r$ has to adjust so that the Euler condition is satisfied. If the economy is constrained in all periods, consumption growth falls on impact, so $r$ must fall. This leads to a fall in the lending spread; but the spread cannot be negative. Consequently, for a large enough increase in $\rho$, the economy must become unconstrained, at least initially: the spread becomes zero, $c$ falls below its old steady state value, and $d$ falls below $\bar{d}$.

Hence, a large enough shock can be contractionary on impact. As in other cases, shocks that are even larger can have effects for more periods, etc. Since the analysis resembles that of other cases in the paper, we leave the details to the interested reader. Just recall that $\rho$ cannot become larger than $\beta^{-1}$ for the steady state to remain constrained. ${ }^{14}$

\footnotetext{
${ }^{14}$ On the other hand, $\rho$ can rise above $\beta^{-1}$ temporarily.
} 


\subsection{Nominal Rigidities and Policy}

Consider prices fixed one period in advance, and suppose that policy keeps the exchange rate fixed at its old steady state value. Denoting the latter by $e^{o}$, the short run equilibrium is given by the external balance condition

$$
(1-\alpha)\left(e^{o}\right)^{-\alpha} c=z+x\left(e^{o}\right)^{\chi-1}
$$

and the market-clearing condition

$$
y=\alpha\left(e^{o}\right)^{(1-\alpha)} c+x\left(e^{o}\right)^{\chi} .
$$

By inspection, it follows that $c=c^{o}$ and $y=y^{o}$. That is, in the period of the shock the economy remains at its original steady state. It moves to the new steady state after one period. Overall, then, a fixed exchange rate policy implies the same outcome as with flexible prices.

By contrast, suppose that policy keeps the real interest rate fixed at its steady state value $\left(1+r=\beta^{-1}\right)$ and lets the exchange rate float. Then, the Euler equation requires that consumption be the same this period and next: $c=\bar{c}$. That is, consumption drops immediately to its new long-run value. The exchange rate is then given by

$$
(1-\alpha) e^{-\alpha} c=z+x e^{\chi-1}
$$

Since $\bar{c}$ is smaller than in the old steady state, this equation implies that the exchange rate must appreciate, provided $\chi$ is not too small. Finally, output is given by the market-clearing condition (1). Output must fall, given the drop in consumption and the appreciation of the exchange rate.

In this case, it is the flexible exchange rate policy (with a fixed interest rate) that is contractionary in the short run. The intuition is that an increase in $\rho$ does not affect the current debt burden, but only the debt service starting one period after the shock. The fixed exchange rate policy takes advantage of that fact and postpones the adjustment, while a flexible interest rate policy brings the adjustment forward.

\subsection{On Unconventional Policy}

For concreteness, focus on the direct lending policy of subsection 6.1, assuming that the central bank has $f$ units of tradables, and lends a constant 
amount $l_{t}^{g}=l^{g}$ to households. In the new steady state, the external constraint becomes:

$$
\begin{array}{r}
\bar{c}=-\bar{e}^{\alpha} \rho^{\prime}\left(\bar{d}+l^{g}\right)+\bar{e}^{-(1-\alpha)} \bar{y}+\bar{e}^{\alpha}\left(z+\rho^{\prime} f\right) \\
=\bar{e}^{\alpha} \rho^{\prime}\left(f-l^{g}-\theta \tilde{k}\right)+\bar{e}^{-(1-\alpha)} \bar{y}+\bar{e}^{\alpha} z
\end{array}
$$

The other steady state equations remain the same.

The implications of a permanently higher world interest rate on the steady state can be the same or the opposite of those in preceding subsections, depending on whether the country as a whole is a net debtor or a net creditor. The above equation reveals that $\bar{c}$ must be greater than $c^{o}$, and $\bar{e}$ and $\bar{y}$ lower than $e^{o}$ and $y^{o}$, if $f-l^{g}-\theta \tilde{k}>0$. The intuition is obvious: the condition holds when the country as a whole is a net creditor in the world market. Then, an increase in the interest rate is just like a permanent windfall increase in $z$ of size $\rho^{\prime}\left(f-l^{g}\right)$.

A key observation here is that the size of the direct credit $l^{g}$ reduces the implicit windfall: a larger $l^{g}$ means that the government is borrowing in the world market on behalf of the representative agent, and that the cost of borrowing is the world interest rate. Equivalently, here a dollar that the central bank lends to households is a dollar that is not invested in the world market, earning the world interest rate.

As noted earlier, one should ask how $l^{g}$ was chosen in the first place. One may also ask what is the optimal path of direct lending (and of other unconventional policies). But regardless, it is worth noticing that for countries that are net creditors (admittedly, not a very large group) a permanent increase in the world interest rate can be beneficial ex post, because it increases earnings

on the net foreign asset position. This effect would have to be taken into account in the analysis of unconventional policies and reserve accumulation.

\section{Concluding Remarks}

Why are emerging markets so vulnerable to shocks? What features of the domestic financial system account for the amplification and persistence of domestic responses to external shocks? Given such features, how can we understand the role of monetary policy, both conventional and unconventional? In this paper we have analyzed plausible answers to these questions, with emphasis on the role played by financial market distortions in shaping an emerging economy's response to external shocks, whether real or financial. 
One conclusion that emerges from our analysis is that the presence and details of borrowing constraints are crucial. The inability to borrow to ease adjustment to shocks determines the behavior of consumption, the real exchange rate, and output, as well as the room for policy to play a role.

A second conclusion is that, with sticky nominal prices, monetary and exchange rate policies make a big difference in determining the nature of the adjustment to different shocks. For instance, if the shock is a temporary drop in endowment of traded goods or a permanent tightening of the borrowing constraint, flexible exchange rates help cushion the shock, while fixed exchange rates cause larger drops in consumption and output. Conversely, if the shock is an increase (whether permanent or transitory) in the world real interest rates, fixed rates help postpone the pain of adjustment, while flexible rates are associated with an immediate recession, and both consumption and output fall right away.

A third conclusion is that unconventional policies have a crucial role to play, but this role is quite different than in advanced economies. In advanced economies, quantitative easing, credit easing, and the like emerged as a response to the zero lower bound. Financial imperfections matter (otherwise the price of long-term paper would be perfectly arbitraged with that of short-term paper, given expectations) but they often have not been seen as an essential part of the story. Indeed, in parts of the academic literature, the effectiveness of unconventional policies is studied in the context of models with perfect financial markets. A good example of that is Benigno and Nistico (2015).

By contrast, the rationale for unconventional policies in emerging markets is, in our view, inextricably tied to the presence of borrowing constraints and other financial imperfections. Indeed, as we argued above, unconventional policies are necessary because conventional monetary policies cannot eliminate the adverse effects of financial distortions in the presence of shocks, and in some circumstances can even aggravate them. Different unconventional policies are at the end of the day different mechanisms for injecting dollar liquidity in to the economy. The choice among them is guided precisely by the need to get the biggest bang for those scarce "bucks" coming from abroad.

Our analysis suggests several directions for future research. One, which follows naturally from the preceding discussion, is to study optimal accumulation and utilization of foreign exchange reserves. From the perspective of this paper, foreign exchange reserves represent a key restriction on the availability of unconventional policies in emerging markets. Since we have shown 
that the latter have real effects when financial frictions bind, an appropriate policy of accumulation of reserves emerges as a priority in the debate.

A second direction is to explore alternative assumptions about finance constraints. For instance, we assumed but did not provide microfoundations for the equity constraint. While we do not believe that to be a serious shortcoming for the analysis in this paper, it may turn out to be important for studying some other questions, such as financial regulation. Perhaps more significantly, we assumed finance constraints of a very simple form. Examining the robustness of our results to other forms, such as dynamic ones, is warranted. 


\section{Appendix}

To describe the solution of the household's problem in the main text, let $\beta^{t} \lambda_{t}$ and $\beta^{t} \gamma_{t}$ denote Lagrange multipliers associated with the budget constraint and the equity constraint. Then the first order conditions for maximization are

$$
\begin{gathered}
\lambda_{t} e_{t}^{\alpha}=\beta \lambda_{t+1}\left(1+\varrho_{t}\right) e_{t+1}^{\alpha} \\
\lambda_{t}=\beta \lambda_{t+1}\left(1+r_{t}\right) \\
\lambda_{t} e_{t}^{\alpha}+\gamma_{t}=\lambda_{t+1}\left(1+\omega_{t}\right)(1+\rho) e_{t+1}^{\alpha} \\
c_{t}^{-\sigma}=\lambda_{t} \\
\eta n_{t}^{\phi}=\lambda_{t} w_{t}
\end{gathered}
$$

The complementarity condition

$$
\gamma_{t} \geq 0,=0 \quad \text { if } \quad k_{t}<\bar{k}
$$

must also hold. These expressions require that, in any equilibrium, (9) must hold. Also (and recalling the definition of $\omega_{t}$ ), $\gamma_{t}=0$ if $\varrho_{t}=\rho$-that is, the household's equity constraint does not bind if the interest spread is zero.

Next, we justify assertions at the end of subsection 4.1. Rewrite the external condition (17) in terms of the domestic good as

$$
e s+x e^{\chi}+e z=m
$$

where $m \equiv(1-\alpha) e^{1-\alpha} c$ is the value of imports. We assume $z>s$, so the preceding expression gives $m$ as an increasing function of $e$, given the shock $s$. This function depends on $s$ : for any $e$, a larger (more negative) shock drives imports $m$ down.

At the same time, combining the labor supply condition and market clearing gives

$$
\mu m^{-1}-\alpha m=(1-\alpha) x e^{\chi}
$$

where $\mu \equiv(1-\alpha)^{2}\left(1-\epsilon^{-1}\right) \eta^{-1}$ The LHS is a decreasing function of $m$ and the RHS is an increasing function of $e$, so this whole expression represents a negatively-sloped relation between $m$ and $e$.

Short-run equilibrium is given by the intersection of these two schedules: this is depicted in Figure 2, where XX is the external constraint (26) and MM is the graph of (27). An adverse shock means that $s$ becomes smaller, 
displacing the XX downwards and resulting in a fall in $m$ and an increase in $e$-that is, a drop in imports and a real depreciation. Then, by the definition of $m, c$ must also fall: consumption drops along with the drop in imports and in the real value of the currency.

In this case, the output supply condition can be written as

$$
(1-\alpha) y=\mu m^{-1} \text {. }
$$

Since $m$ falls, $y$ must increase. The shock is expansionary for supply reasons: as consumption and the real exchange rate drop, the marginal utility of consumption rises. Labor supply and output then rise to keep utilities equated at the margin.

Finally, since $c$ falls and $e$ increases, while $\bar{c}$ and $\bar{e}$ are the same as in the original steady state, the Euler equation (18) implies that $\varrho$ increases above its steady state value. 


\section{References}

[1] Caballero, R. and A. Krishnamurthy, "Excessive Dollar Debt: Financial Development and Underinsurance“, Journal of Finance 58, 2 (2003), 867-893.

[2] Calvo, G. and C. Reinhart, "Fear of Floating", Quarterly Journal of Economics (2002) 117 (2): 379-408

[3] Céspedes, L., R. Chang and A. Velasco, "Is Inflation Target Still on Target? The Recent Experience of Latin America", International Finance 17,2 (2014), 185-207

[4] Céspedes, L., R. Chang and A. Velasco, "Financial Intermediation, Exchange Rates, and Unconventional Policy in an Open Economy", manuscript, 2015.

[5] Chang, R. , "Inflation Targeting, Reserves Accumulation, and Exchange Rate Management in Latin America," Papers and Proceedings, II International FLAR Conference, Fondo Latinoamericano de Reservas, 2007.

[6] Eggertsson, G. and P. Krugman, "Debt, Deleveraging, and the Liquidity Trap: A Fisher-Minsky-Koo Approach “, Quarterly Journal of Economics 127 (2012), 1469-1513

[7] Gertler, M. and N. Kiyotaki, "Financial Intermediation and Credit Policy in Business Cycle Analysis," Handbook of Monetary Economics, 2010 .

[8] Montoro, C. and R. Moreno, "The use of reserve requirements as a policy instrument in Latin America," BIS Quarterly Review, Bank for International Settlements, March 2011

[9] Romer, D., "Short Run Fluctuations", manuscript, 2013

[10] Woodford, M., "Financial Intermediation and Macroeconomic Analysis ", Journal of Financial Intermediation 24 (Fall 2010), 21-44 

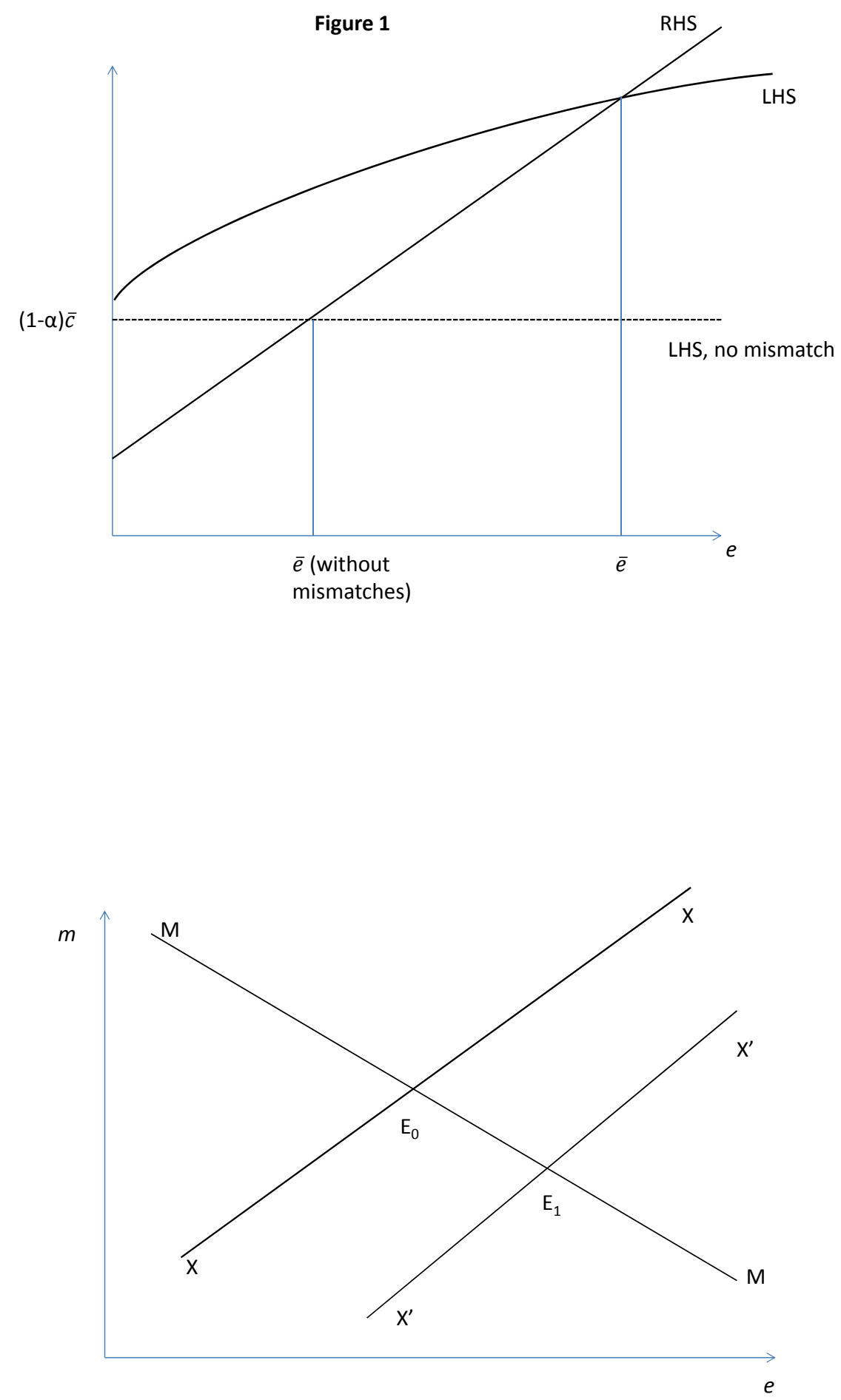

Figure 2 